\title{
CLINICO-PATHOLOGICAL STUDY OF THYROID LESIONS OVER A PERIOD OF ONE YEAR IN A TERTIARY CARE CENTRE
}

\author{
Metta Raja Gopal1, Konkena Janardhana Rao², Adusumalli Ramya Sai ${ }^{3}$
}

1 Professor, Department of Surgery, RIMS, Srikakulam, Andhra Pradesh, India.

${ }^{2}$ Associate Professor, Department of Surgery, RIMS, Kadapa, Andhra Pradesh, India.

${ }^{3}$ Postgraduate Student, Department of Surgery, Andhra Medical College, Visakhapatnam, Andhra Pradesh, India.

\section{ABSTRACT}

\section{BACKGROUND}

Thyroid diseases are one of the common endocrine abnormalities, both in India and worldwide. Diseases of the thyroid are of great importance because they are most amenable to medical or surgical management.

The objectives of this study are 1. to evaluate the age and sex distribution of various thyroid lesions 2 . to assess its prevalence and 3. to compare its clinical presentation with histopathology.

\section{MATERIALS AND METHODS}

The present study is a descriptive study conducted for a period of one year from Jan 2015 to December 2015, conducted in the Department of Surgery, King George Hospital, Visakhapatnam. Clinical details were recorded as per the proforma. Tissue for H and E sections were fixed in 10\% formalin and subjected to routine paraffin embedded processing and stained with Haematoxylin and Eosin.

\section{RESULTS}

Out of total 72 cases of thyroid lesions, maximum number of lesions were seen in patients in the age group of $31-40$ years (n= 21, $29.16 \%$ ) with females being more commonly affected than males and with male-to-female ratio of 1:11. Most common clinical symptom was midline neck swelling. Out of 72 cases, 56 cases (77.78\%) were diagnosed as non-neoplastic and remaining 16 cases $(22.22 \%)$ as neoplastic.

\section{CONCLUSION}

Combined opinion on nature of thyroid lesion should be done based on history, clinical examination and ultrasonographic features. Histopathological diagnosis of thyroid lesions is important for early diagnosis and treatment of neoplastic lesions.

\section{KEY WORDS}

Thyroid, Malignancy, Papillary Carcinoma.

HOW TO CITE THIS ARTICLE: Gopal MR, Rao KJ, Sai AR. Clinico-pathological study of thyroid lesions over a period of one year in a tertiary care centre. J. Evolution Med. Dent. Sci. 2018;7(31):3513-3517, DOI: 10.14260/jemds/2018/790

\section{BACKGROUND}

Thyroid lesions are fairly common worldwide and are commonly encountered in clinical practice. ${ }^{1}$ Thyroid swellings are very superficial, easily visible and display an intriguing range of lesions, widely differing in biological behaviour and are source of concern for the patient and a diagnostic dilemma for physicians. ${ }^{2}$

Clinically, apparent thyroid nodules are seen in $4-5 \%$ of population. Majority of thyroid swellings are non-neoplastic, only $<5 \%$ are malignant. ${ }^{3}$ Thyroid lesions may be developmental, inflammatory, hyperplastic and neoplastic. The surgical excision of the nodule and its histological examination is the only way to differentiate between the more frequent benign and much less frequent malignant nodules. ${ }^{4}$

Accurate diagnosis of thyroid nodule is necessary for appropriate clinical management of patients and to avoid unnecessary surgical interventions.

'Financial or Other Competing Interest': None.

Submission 07-06-2018, Peer Review 13-07-2018,

Acceptance 20-07-2018, Published 30-07-2018.

Corresponding Author:

Dr. Konkena Janardhana Rao,

Associate Professor,

RIMS, Kadapa, Andhra Pradesh, India.

E-mail: kjrvskp@gmail.com

DOI: $10.14260 /$ jemds $/ 2018 / 790$

\section{(c) (i) $\odot$}

The present study is a clinico-pathological study of thyroid lesions in a tertiary care centre with the main objectives of studying the spectrum of diseases in thyroid swellings along with its histopathology.

\section{MATERIALS AND METHODS}

\section{Study Design}

The present study is a descriptive study for a period of one year from Jan 2015 to December 2015, conducted in the Department of Surgery, King George Hospital, Visakhapatnam.

\section{Inclusion Criteria}

Hemithyroidectomy, subtotal thyroidectomy and total thyroidectomy specimens received for histopathological examination suspected for neoplastic and non-neoplastic lesions of thyroid.

\section{Exclusion Criteria}

Recurrent lesions and cases on therapy were excluded from the study.

\section{Study Subjects}

In this study, a total of 72 patients with thyroid swellings were taken attending Surgery Department were selected. A complete history of the patient pertaining to complaints were obtained. The clinical details were recorded as per the 
proforma along with Ultrasonographic (USG) findings and related investigations were taken into consideration. Fine needle aspiration was done by using non-aspiration technique except for cystic lesions. In case of non-diagnostic aspirates, the procedure was repeated.

Post-operatively, the cases were followed. Specimens were collected in $10 \%$ formalin in fresh state and allowed to fix for 24 hours.

Detailed gross examination was done, and bits were given. Paraffin-embedded Haematoxylin and eosin-stained sections were obtained and studied under light microscopy. The tumours were classified based on WHO classification of thyroid tumours.

Data was analysed using SPSS Software Version 13.

\section{RESULTS}

In the present study, a total of 72 patients with thyroid swellings were taken for the study for a period of one year from Jan 2015 to December 2015.

The age of the patients ranged from 5 years to 70 years with a mean age of 35 years. Maximum number of lesions were seen in patients in the age group of $31-40$ years $(n=21$, $29.16 \%)$ followed by $21-30$ years $(n=16,22.22 \%)$ and 41 50 years $(n=15,20.83 \%)$ (Table 1$)$.

In the present study, a female predilection was seen. It was observed that $66(91.66 \%)$ cases were females and $6(8.33 \%)$ cases were male (Table 2$)$. Male-to-female ratio was noted to be 1: 11 . Most common age group affected in females were 31 - 40 years, comprising of 19 cases $26.38 \%$ (Table 3).

In the present study, most common clinical symptom was midline neck swelling seen in almost all cases (69 cases 95.83\%) followed by menstrual irregularity (12 cases $16.66 \%$ ) and dyspnoea ( 1 case $-1.38 \%$ ). Out of 72 cases, 35 (48.61\%) patients presented with thyroid swelling involving right lobe followed by 31 patients $(43.05 \%)$ involving left lobe and 6 patients $(8.33 \%)$ presented with diffuse thyroid swelling (Table 4).

In the present study, all patients underwent ultrasonography where the majority of patients were reported with colloid goitre (42 cases - 58.33\%) followed by multinodular goitre (13 cases - 18.05\%), solitary thyroid nodule ( 9 cases - 12.5\%) (Figure 1) and thyroiditis ( 2 cases $2.77 \%$ ) (Table 5).

In the present study, out of total 72 cases 56 cases (77.78\%) were diagnosed as non-neoplastic and remaining 16 cases $(22.22 \%)$ as neoplastic.

In the present study among non-neoplastic lesions, simple colloid goitre 39 cases (69.64\%) was found to be the most common followed by multinodular goitre 9 cases $(16.07 \%)$, Hashimoto's thyroiditis 7 cases (12.5\%) and granulomatous thyroiditis 1 case $(1.78 \%)$.

In the present study, among neoplastic cases follicular adenoma ( 8 cases $-50 \%$ ) was found to be the most common followed by papillary carcinoma (4 cases - 25\%), (Figure 2, 3) follicular carcinoma ( 3 cases - 18.75\%) and Medullary carcinoma (1 case - 6.25\%) (Figure 4). Ratio of nonneoplastic to neoplastic lesions is 3.5: 1 (Table 6). Out of 42 clinically diagnosed cases of colloid goitre 39 cases were consistent with histopathological diagnosis, 2 cases turned out to be follicular adenoma and the other as multinodular goitre.

Out of 13 clinically diagnosed cases of multinodular goitre 9 cases correlated with histopathological diagnosis, 2 cases turned out to be Hashimoto's thyroiditis, one case was follicular adenoma and the other case was papillary carcinoma.

Out of 4 clinically diagnosed cases of solitary thyroid nodule 2 cases turned out to be papillary carcinoma, out of which one was follicular variant of papillary carcinoma, 2 cases turned out to be multinodular goitre.

Out of 5 clinically diagnosed cases of papillary carcinoma, 2 were consistent with the histopathological diagnosis, whereas out of the other 3 deferred cases one case turned out to be multinodular goitre, one was Hashimoto's thyroiditis and the other turned out to be medullary carcinoma.

\begin{tabular}{|c|c|c|}
\hline Age & No. of Cases & Percentage (\%) \\
\hline $0-10$ & 1 & 1.38 \\
\hline $11-20$ & 4 & 5.55 \\
\hline $21-30$ & 16 & 22.22 \\
\hline $31-40$ & 21 & 29.16 \\
\hline $41-50$ & 15 & 20.83 \\
\hline $51-60$ & 14 & 19.44 \\
\hline $61-70$ & 1 & 1.38 \\
\hline Total & $\mathbf{7 2}$ & $\mathbf{1 0 0}$ \\
\hline Table 1. Age Wise distribution of Thyroid Lesions (n= 72)
\end{tabular}

Table 1. Age Wise distribution of Thyroid Lesions $(n=72)$

\begin{tabular}{|c|c|c|}
\hline Sex & No. of Cases & Percentage (\%) \\
\hline Female & 66 & $91.67 \%$ \\
\hline Male & 6 & $8.33 \%$ \\
\hline Total & $\mathbf{7 2}$ & $\mathbf{1 0 0}$ \\
\hline
\end{tabular}

Table 2. Sex Wise distribution of Thyroid Lesions $(n=72)$

\begin{tabular}{|c|c|c|c|}
\hline Age & Male & Female & Total \\
\hline $0-10$ & 0 & 1 & 1 \\
\hline $11-20$ & 1 & 3 & 4 \\
\hline $21-30$ & 1 & 15 & 16 \\
\hline $31-40$ & 2 & 19 & 21 \\
\hline $41-50$ & 1 & 14 & 15 \\
\hline $51-60$ & 1 & 13 & 14 \\
\hline $61-70$ & 0 & 1 & 1 \\
\hline Total & 6 & 66 & 72 \\
\hline Table 3. Age and Sex distribution of Thyroid Lesions \\
$(n=72)$ \\
\hline
\end{tabular}

\begin{tabular}{|c|c|c|}
\hline Clinical Symptoms & No. of Cases & (\%) \\
\hline Midline neck swelling & 69 & $95.83 \%$ \\
\hline Menstrual irregularity & 12 & $16.66 \%$ \\
\hline Dyspnoea & 1 & $1.38 \%$ \\
\hline Hoarseness of voice & 1 & $1.38 \%$ \\
\hline \multicolumn{2}{|c|}{ Table 4. Clinical Symptoms in Cases with Thyroid Lesions } \\
\hline
\end{tabular}

\begin{tabular}{|c|c|c|}
\hline USG Findings & No. of Cases & (\%) \\
\hline Colloid goitre & 42 & $58.33 \%$ \\
\hline Multinodular goitre & 13 & $18.05 \%$ \\
\hline Solitary thyroid nodule & 9 & $12.5 \%$ \\
\hline Thyroiditis & 2 & $2.77 \%$ \\
\hline
\end{tabular}




\begin{tabular}{|c|c|c|c|}
\hline $\begin{array}{c}\text { Thyroid } \\
\text { Lesions }\end{array}$ & $\begin{array}{c}\text { Histopathological } \\
\text { Diagnosis }\end{array}$ & $\begin{array}{c}\text { No. of } \\
\text { Cases }\end{array}$ & $\begin{array}{c}\text { Percentage of } \\
\text { Cases (\%) }\end{array}$ \\
\hline \multirow{4}{*}{$\begin{array}{c}\text { Non- } \\
\text { neoplastic }\end{array}$} & Simple colloid goitre & 39 & $69.64 \%$ \\
\cline { 2 - 4 } & Multinodular goitre & 9 & $16.07 \%$ \\
\cline { 2 - 4 } & $\begin{array}{c}\text { Hashimoto's } \\
\text { thyroiditis }\end{array}$ & 7 & $12.5 \%$ \\
\cline { 2 - 4 } & $\begin{array}{c}\text { Granulomatous } \\
\text { thyroiditis }\end{array}$ & 1 & $1.78 \%$ \\
\hline \multirow{4}{*}{ Neoplastic } & Follicular adenoma & 8 & $50 \%$ \\
\cline { 2 - 4 } & Papillary carcinoma & 4 & $25 \%$ \\
\cline { 2 - 4 } & Follicular carcinoma & 3 & $18.75 \%$ \\
\cline { 2 - 4 } Medullary carcinoma & 1 & $6.25 \%$ \\
\hline \multirow{2}{*}{ Table 6. Distribution of Non-Neoplastic and Neoplastic } \\
\multicolumn{4}{|c|}{ Lesions of Thyroid } \\
\hline
\end{tabular}

\begin{tabular}{|c|c|c|}
\hline Studies & Age Range (Years) & Mean Age \\
\hline Handa et al 6 & 5 - 80 yrs. & 37.69 yrs. \\
\hline Gupta et al ${ }^{8}$ & $22-58$ yrs. & 38.72 yrs. \\
\hline Sameep et al ${ }^{7}$ & $10-80$ yrs. & 38.50 yrs. \\
\hline Present study & $5-85$ yrs. & 35 yrs. \\
\hline \multicolumn{3}{|c|}{$\begin{array}{c}\text { Table 7. Age Range in different studies in } \\
\text { comparison with Present Study }\end{array}$} \\
\hline
\end{tabular}

\begin{tabular}{|c|c|c|c|}
\hline Studies & Non-Neoplastic & Neoplastic & Ratio \\
\hline Sangalli et al 20 & 3343 & 2126 & 1.57: 1 \\
\hline Tabaqchali et al21 & 145 & 94 & 1.54: 1 \\
\hline Uma Handa et al ${ }^{6}$ & 54 & 12 & 4.5: 1 \\
\hline Present Study & 56 & 16 & $3.5: 1$ \\
\hline \multicolumn{4}{|c|}{$\begin{array}{c}\text { Table 8. Distribution of Non-Neoplastic to Neoplastic } \\
\text { Lesions in different Studies }\end{array}$} \\
\hline
\end{tabular}

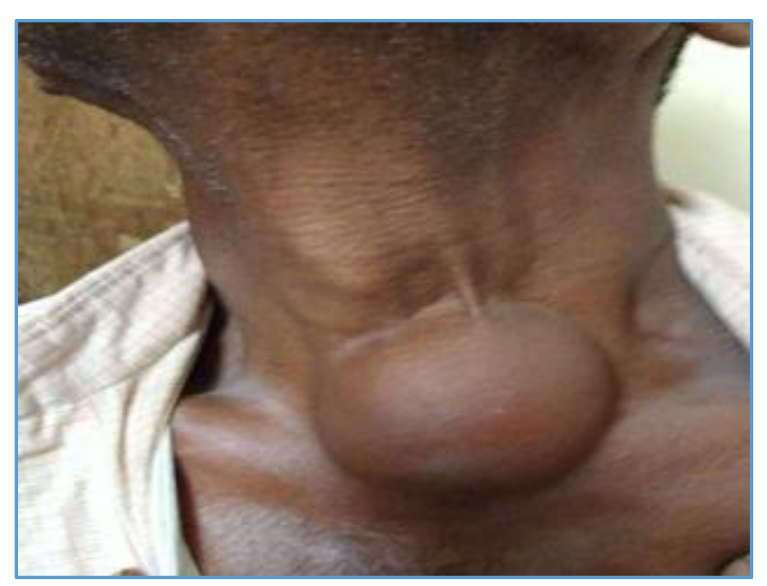

Figure 1. Elderly Male with Solitary Nodule Thyroid

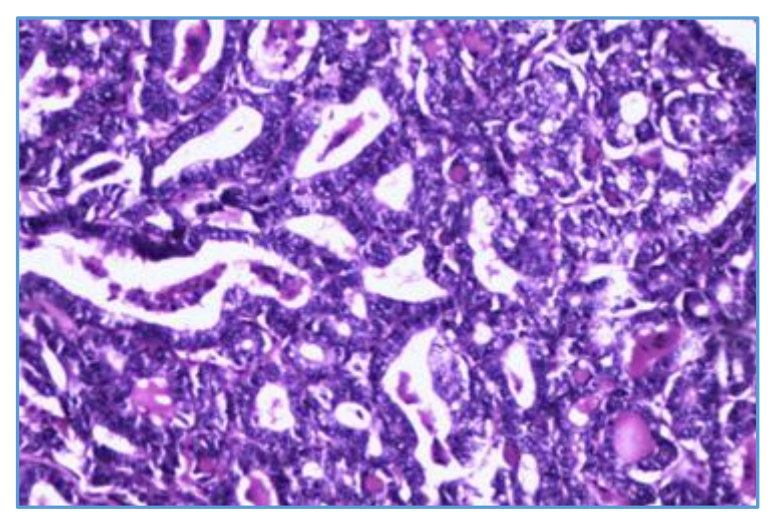

Figure 2. Photomicrograph of Follicular variant of Papillary Carcinoma showing Follicular Arrangement of Tumour Cells with Ground Glass Nuclei (H and E, 100X)

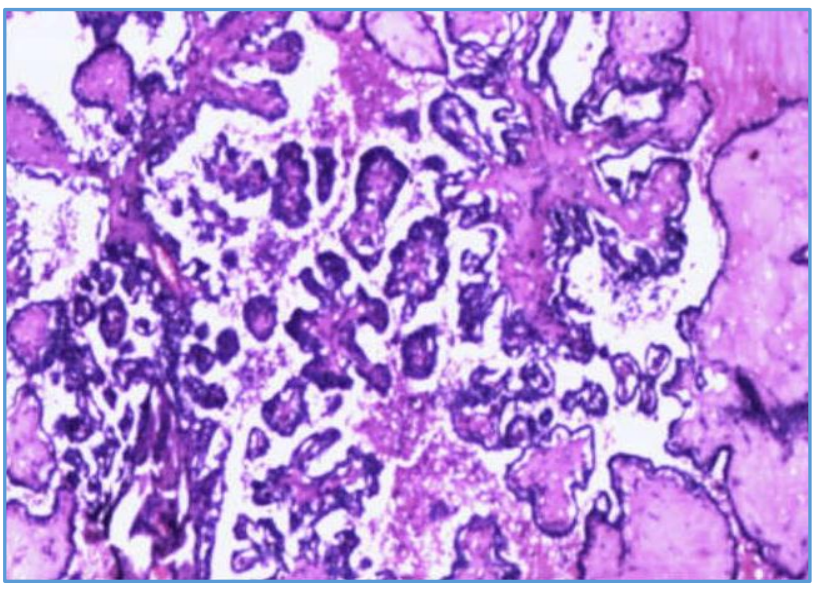

Figure 3. Photomicrograph of Papillary Carcinoma showing Typical Arborizing Papillae with Fibrovascular Core (H and E, 40X)

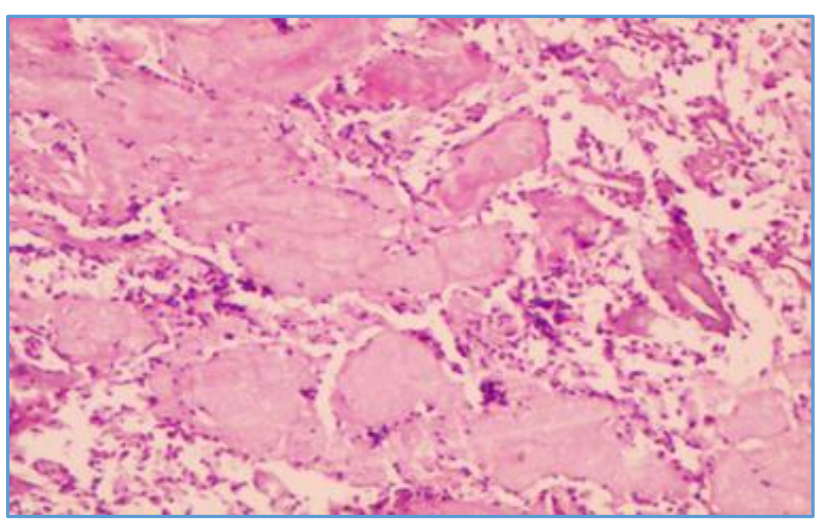

Figure 4. Photomicrograph of Medullary Carcinoma showing Homogeneous Pink Amyloid-Like Material (H and $E, 100 X)$

\section{DISCUSSION}

Occurrence of thyroid diseases vary according to different geographical areas, age and sex. ${ }^{5}$ In the present study, an attempt was made to figure out the histopathological pattern of thyroid diseases in those undergoing thyroidectomies along with their clinico-radiological details.

In the present study, the age of the patients ranged from 5 years to 70 years with a mean age of 35 years. This was similar to Handa et al ${ }^{6}$ and Sameep et al, ${ }^{7}$ which showed 5-80 years. The mean age was similar to studies done by Handa et al,6 Gupta et $\mathrm{al}^{8}$ and Sameep et al ${ }^{7}$ with values of 37.69 years, 38.72 years and 38.50 years respectively (Table 7).

In this study out of total 72 cases, 56 cases $(91.66 \%)$ were female and 6 cases $(8.33 \%)$ were male with male: female ratio of 1: 11 . This was similar to Handa et $\mathrm{al}^{6}$ and Sameep et al, ${ }^{7}$ which showed similar 1:11 ratio. The present study also correlated with the studies conducted by Ghazaleh et al ${ }^{9}$ (16\% male and $84 \%$ female), Alam et al ${ }^{10}$ (13\% male and $87 \%$ female) and Sathiyamurthy et al 11 (20\% male and $80 \%$ female).

Swelling in the neck was the most common clinical presentation noted in this study, similar to the findings seen in Karthik Kathladka et al ${ }^{12}(100 \%)$ and Hanumanthappa et $\mathrm{al}^{13}(92 \%)$. Local compressive symptoms such as dyspnoea, dysphagia, menstrual irregularities, lymphadenopathy and weight related problems were the other associated symptoms observed. In study conducted by Prakash A et al,14 thyroid 
swelling was in $95.5 \%$ cases and Godinho-Matos L et al,15 the thyroid swelling was present in $100 \%$ cases, dyspnoea in $3 \%$ cases and hoarseness of voice in $3 \%$ cases.

The variability of various lesions could be due to studies being conducted on different population of various countries and variable influences of geographical, environmental, dietary and hereditary factors.

Ultrasonography (USG) is used to establish physical characteristics like size, shape and number of nodules. ${ }^{4}$ In the present study, colloid goitre (42 cases - 58.33\%) was the most common finding on USG followed by multinodular goitre comprising of (13 cases - 18.05\%). Similar study conducted by Gupta et al, ${ }^{4}$ multinodular goitre (55\%) was the most common ultrasonographic finding followed by solitary thyroid nodule (19\%).

In the present study, total thyroidectomies included were $36.4 \%$ and hemithyroidectomy specimens were $56.7 \%$. Chetan VR et al ${ }^{16}$ study noted hemi-thyroidectomies that comprised of $66 \%$ compared to just $10 \%$ of hemithyroidectomies in Karthik Kathladka et al ${ }^{12}$ study. In a study by Mattioli FP et al, ${ }^{17}$ subtotal thyroidectomy was shown to be an adequate surgical intervention for MNG. In a review by Masslot et al ${ }^{18}$ they preferred total thyroidectomy over subtotal thyroidectomy, as the later procedure may require re-intervention in the long-term follow-up and subsequent surgeries had higher chances of complications like hypoparathyroidism and recurrent laryngeal nerve palsy. Kartikeyan et al $^{19}$ study showed that subtotal thyroidectomy has reduced incidence of complications, but increased risk of recurrence. As complications are more common in secondlook surgeries, it is preferable to perform total thyroidectomy.

The distribution of non-neoplastic and neoplastic lesions was similar to Uma Handa et al, 6 but higher compared to studies by Sangalli et $\mathrm{al}^{20}$ and Tabaqchali et al ${ }^{21}$ (Table 8).

Among non-neoplastic lesions colloid goitre was the most common lesion 39 cases (69.64\%) followed by multinodular goitre 9 cases $(16.07 \%)$. Magdalene et al ${ }^{22}$ noted colloid goitre $(42 \%)$ was the most common lesion in their studies and Kusum et $\mathrm{al}^{23}$ as multinodular goitre $(73 \%)$ followed by adenomatous goitre (8\%).

In the present study, benign tumours were more common than malignant tumours. Out of 72 cases, 16 cases were neoplastic. Out of this, 8 cases (50\%) were benign tumours and 8 cases $(50 \%)$ were malignant tumours. This was similar to Uma Handa et $\mathrm{al}^{6}$ study, but higher compared to Kessler et $\mathrm{al}^{24}$ and Haberal et $\mathrm{al}^{25}$ studies.

The clinical presentation of benign thyroid swellings has varied benign pathological diagnosis. Follicular adenoma was the most common benign tumour ( 8 cases - $11.11 \%$ ) which correlated with studies conducted by Gupta et al 8 (16\%), Silverman et $\operatorname{al}^{26}(5.2 \%)$ and Sathiyamurthy et al ${ }^{11}$ (5.45\%), but higher than Handa et $a^{6}$ (1.84\%).

In the present study, papillary carcinoma was the most common malignant tumour accounting for 4 cases (5.56\%). Papillary carcinoma of follicular variant was diagnosed in 1 case $(25 \%)$, which was similar compared to study conducted by Nart et $\mathrm{al}^{27}(15.3 \%)$.

Medullary carcinoma was diagnosed in 1 case in a 41year-old female $(0.47 \%)$, which was similar to studies conducted by Silverman et al $9(0.6 \%)$, Handa et $\mathrm{al}^{6}(0.69 \%)$,
Sathiyamurthy et $\mathrm{al}^{11}(0.90 \%)$, but the incidence was much lower than Nart et $\mathrm{al}^{27}(5.4 \%)$ and Nggada et al ${ }^{28}$ (4.3\%).

\section{CONCLUSION}

Combined opinion on nature of thyroid lesion should be done based on history, clinical examination and ultrasonographic features. Histopathological diagnosis of thyroid lesions is important for early diagnosis and treatment of neoplastic lesions. Thyroidectomy may have both therapeutic and diagnostic value. This study emphasises the need of periodic evaluation in middle-aged female patients with multinodular goitre for early detection of papillary carcinoma. Early diagnosis and excision of lesion will provide comfort for the patient and also decrease the problems arising from malignant lesions.

\section{REFERENCES}

[1] Tsegaye B, Ergete W. Histopathologic pattern of thyroid disease. East African Medical Journal 2003;80(10):525-8.

[2] Mandreker SR, Nadkarni NS, Pinto RG, et al. Role of fine needle aspiration cytology as the initial modality in the investigation of thyroid lesions. Acta Cytol 1995;39(5):898-904.

[3] Sukumaran R, Kattoor J, Pillai KR, et al. Fine needle aspiration cytology of thyroid lesions and its correlation with histopathology in a series of 248 patients. Indian J Surg Oncol 2014;5(3):237-41.

[4] Gupta A, Jaipal D, Kulhari S, et al. Histopathological study of thyroid lesions and correlation with ultrasonography and thyroid profile in western zone of Rajasthan, India. Int J Res Med Sci 2016;4(4):12048.

[5] Antony J, Celine TM, Chacko M. Spectrum of thyroid disorders: a retrospective study at a medical college hospital. Thyroid Res Pract 2014;11(2):55-9.

[6] Handa U, Garg S, Mohan H, et al. Role of fine needle aspiration cytology in diagnosis and management of thyroid lesions: a study on 434 patients. J Cytol 2008;25:(1):13-7.

[7] Garg S, Desai NJ, Mehta D, et al. To establish Bethesda system for diagnosis of thyroid nodules on the basis of fnac with histopathological correlation. Journal of Clinical and Diagnostic Research 2015;9(12):EC17EC21.

[8] Gupta M, Gupta S, Gupta VB. Correlation of fine needle aspiration cytology with histopathology in the diagnosis of solitary thyroid nodule. J Thyroid Res 2010;2010:379051.

[9] Ghazaleh N, Haddadinezhad S, Jafari M. Fine needle aspiration cytology of thyroid nodules: correlation with surgical histopathology. Terk Jem 2008;12:73-4.

[10] Alam M, Qureshi H, Jan QA. Accuracy of FNAC as a diagnostic modality in the management of solitary thyroid nodule. J Med Sci 2010;18:94-6.

[11] Sathiyamurthy K, Patil MS, Mirje M. Fine needle aspiration cytology study of thyroid lesions. International Journal of Curr Research 2014;6(10):9230-3. 
[12] Sanjeeva KK, Chandra B, Balakrishna MA, et al. Clinicoepidemiological study and treatment outcome of multinodular goitre at a tertiary care hospital. Journal of Clinical and Diagnostic Research 2015;9(6):PC22PC5.

[13] Hanumanthappa MB, Gopinathan S, Suvarna R, et al. The incidence of malignancy in multi-nodular goitre: a prospective study at tertiary academic centre. Journal of Clinical and Diagnostic Research 2012;6(2):267-70.

[14] Prakash A, Moulik BK, Sharma LK, et al. Carcinoma of thyroid gland: a clinical study. Ind J Surg 1974;43:40916.

[15] Godinho-Matos L, Kocjan G, Kurtz A. Contribution of fine needle aspiration cytology to diagnosis and management of thyroid disease. J Clin Pathol 1992;45(5):391-5.

[16] Chetan RV, Veeresalingam B, Kumar KM, et al. A study on the clinical manifestations and the incidence of benign and malignant tumors in a solitary thyroid nodule. International Journal of Research in Medical Sciences 2013;1(4):429-34.

[17] Mattioli F, Torre GC, Borgonovo G, et al. Surgical treatment of multinodular goitre. Ann Ital Chir 1996;67(3):341-5.

[18] Masslot ET, Peeters RP. What is the optimal treatment for benign multinodular goitre? The Netherlands Journal of Medicine 2015;73(1):2-3.

[19] Selvaraju K, Shetty P. Outcome of surgery for thyroid diseases. Webmed Central Endocrine Surgery 2013;4(1):WMC003932.

[20] Sangalli G, Serio G, Zampatti C, et al. Fine needle aspiration cytology of the thyroid: a comparision of 5469 cytological and final histological diagnoses. Cytopathology 2006;17(5):245-50.
[21] Tabaqchali MA, Hanson JM, Johnson SJ, et al. Thyroid aspiration cytology in Newcastle: a six year cytology/histology correlation study. Ann R Coll Surg Engl 2000;82(3):149-55.

[22] Magdalene KF, Swetha J, Narayanan N, et al. Histopathological study of thyroid lesions in a tertiary care center in coastal belt of South India. Trop J Path Micro 2017;3(1):77-83.

[23] Borsaikia K, Patar M. Clinicopathological Study of thyroid swellings with some emphasis on geographical and community distribution: a hospital based analysis. Bengal Journal of Otolaryngology and Head Neck Surgery 2016;24(2):75-9.

[24] Kessler A, Gavriel H, Zahav S, et al. Accuracy and consistency of fine-needle aspiration biopsy in the diagnosis and management of solitary thyroid nodules. Isr Med Assoc J 2005;7(6):371-3.

[25] Haberal AN, Toru S, Ozen O, et al. Diagnostic pitfalls in the evaluation of fine needle aspiration cytology of the thyroid: correlation with histopathology in 260 cases. Cytopathology 2009;20(2):103-8.

[26] Silverman FJ, West RL, Larkin EW, et al. The role of fine needle aspiration biopsy in the rapid diagnosis and management of thyroid neoplasm. Cancer 1986;57(6):1164-70.

[27] Nart D, Ertan Y, Argon A, et al. Role of fine needle aspiration cytology and intraoperative diagnosis in the diagnosis of thyroid nodules. Turk J Pathol 2010;26(1):48-54.

[28] Nggada HA, Musa AB, Gali BM, et al. Fine needle aspiration cytology of thyroid nodule(s): a Nigerian tertiary hospital experience. The Internet $\mathrm{J}$ of Pathology 2006;5:1-8. 